\title{
Predictive value of the usual clinical signs and laboratory tests in the diagnosis of septic arthritis
}

\author{
Marion Couderc, MD*; Bruno Pereira, $\mathrm{MD}^{\dagger}$; Sylvain Mathieu, MD*; Jeannot Schmidt, $\mathrm{PhD}^{\ddagger}$; \\ Olivier Lesens, $\mathrm{PhD}^{\S}$; Richard Bonnet, $\mathrm{PhD}^{\Uparrow}$; Martin Soubrier, PhD*; Jean-Jacques Dubost, $\mathrm{MD}^{*}$
}

\section{ABSTRACT}

Objective: To determine the sensitivity and specificity of clinical and laboratory signs for the diagnosis of septic arthritis (SA).

Patients and methods: This prospective study included all adult patients with suspected SA seen in the emergency department or rheumatology department at the University Hospital, Clermont-Ferrand, France, over a period of 18 months.

Results: In total, 105 patients with suspected SA were included, 38 (36\%) presenting with SA (29 [28\%] with bacteriologically documented SA). In the univariate analysis, chills $(p=0.015)$, gradual onset $(p=0.04)$, local redness $(p=0.01)$, as well as an entry site for infection $(p=0.01)$ were most often identified in SA. A history of crystal-induced arthritis $(p=0.004)$ was more frequent in non-SA cases. An erythrocyte sedimentation rate $(E S R)>50 \mathrm{~mm}(p=0.005)$, a C-reactive protein (CRP) level $>100 \mathrm{mg} / \mathrm{L}(p=0.019)$, and radiological signs suggestive of $\mathrm{SA}(p=0.001)$ were more frequent in the SA cases. Synovial fluid appearance: purulent $(p<0.001)$ and clear $(p=0.007)$, synovial white blood cell (WBC) count $>50,000 / \mu \mathrm{L}(p<0.001)$, differentiated between SA and non-SA.

In multivariate analysis, only chills (odds ration $[\mathrm{OR}]=4.7$, 95\% confidence interval [Cl] 1.3-17.1), a history of crystalinduced arthritis $(\mathrm{OR}=0.09,95 \% \mathrm{Cl} 0.01-0.9)$, purulent appearance of the joint fluid (OR $=8.4,95 \% \mathrm{Cl} 2.4-28.5)$, synovial WBC count $>50,000 / \mathrm{mm}^{3}$ (OR $\left.=6.8,95 \% \mathrm{Cl} 1.3-36\right)$, and radiological findings ( $\mathrm{OR}=7.1,95 \% \mathrm{Cl} 13-37.9)$ remained significant.

Conclusion: No clinical sign or laboratory test (excluding bacteriological test), taken alone, is conclusive for the differentiation between SA and non-SA, but the association of several signs, notably chills, history of crystal-induced arthritis, radiological findings, and the appearance and cellularity of joint fluid may be suggestive.

\section{RÉSUMÉ}

Objectif: L'étude visait à déterminer la sensibilité et la spécificité des signes cliniques et des résultats d'examens de laboratoire dans le diagnostic de l'arthrite septique (AS).
Patients et méthode: II s'agit d'une étude prospective à laquelle ont participé tous les adultes souffrant d'AS présumée, et examinés au service des urgences ou au service de rhumatologie de I'hôpital universitaire de Clermont-Ferrand, en France, sur une période de 18 mois.

Résultats: Au total, 105 patients souffrant d'AS présumée ont été retenus; sur ce nombre, 38 (36\%) étaient atteints d'AS (AS avérée bactériologiquement: 29). D'après I'analyse univariée, les frissons $(p=0,015)$, un début progressif $(p=0,04)$, une rougeur locale $(p=0,01)$ ainsi qu'un point d'entrée d'infection $(p=0,01)$ étaient des signes très souvent relevés dans les cas d'AS. Des antécédents d'arthrite causée par le dépôt de cristaux $(p=0,004)$ étaient plus fréquents dans les cas $\mathrm{d}^{\prime}$ arthrite non septique (ANS). Une vitesse de sédimentation des érythrocytes (VSE) $>50 \mathrm{~mm}(p=0,005)$, un taux de protéine $C$ réactive $(C R P)>100 \mathrm{mg} / \mathrm{l}(p=0,019)$ et des signes radiologiques évocateurs d'AS $(p=0,001)$ étaient relevés plus souvent dans les cas d'AS. L'aspect du liquide synovial: purulent $(p<0,001)$ ou clair $(p=0,007)$, et un taux de leucocyte $>50000 / \mu \mathrm{l}(p<0,001)$ dans le liquide synovial permettaient de différencier I'AS de I'ANS.

D'après l'analyse multivariée, seuls les frissons (RRA [risque relatif approché] $=4,7$; IC à $95 \%$ : 1,3-17,1), les antécédents d'arthrite causée par le dépôt de cristaux (RRA $=0,09$; IC à $95 \%$ : 0,01-0,9), I'aspect purulent du liquide articulaire (RRA = 8,4 ; IC à $95 \%$ : 2,4-28,5), une leucocytémie $>50 \quad 000 / \mathrm{mm}^{3}$ (RRA = 6,8; IC à $95 \%$ : 1,3-36) dans le liquide synovial et des signes radiologiques évocateurs (RRA $=7,1$; IC à $95 \%$ : 13-37,9) ont gardé une valeur significative.

Conclusions: Aucun signe clinique ou résultat d'examen de laboratoire (à l'exception des analyses bactériologiques) ne permet à lui seul de distinguer I'AS de I'ANS; toutefois, I'association de plusieurs signes, notamment de frissons, d'antécédents d'arthrite causée par le dépôt de cristaux, de signes radiologiques, de même que l'aspect du liquide articulaire et le nombre de cellules présentes, peut être évocatrice de l'affection.

Keywords: septic arthritis, diagnosis, acute arthritis, microcrystal-induced arthritis

From the *Rheumatology Department; †Biostatistics Unit, DRCl; ¥Emergency Department; §Infectious Diseases Department; and $\llbracket$ Bacteriological Laboratory, University Hospital, Clermont-Ferrand, France.

Correspondence to: Dr. Marion Couderc, Rheumatology Department, Clermont-Ferrand University Hospital, Place Henri Dunant, 63000 ClermontFerrand, France; Email: mcouderc@chu-clermontferrand.fr 


\section{INTRODUCTION}

Septic arthritis (SA) is serious. Mortality is greater than $10 \%$, and close to half of the patients have sequelae related to irreversible damage to cartilage and joint destruction. ${ }^{1}$ The prognosis is worsened by any therapeutic delay, so early diagnosis is essential.

The diagnosis of SA is confirmed by the detection of a microorganism in the joint. However, direct Gram stain is positive in only $25 \%$ to $50 \%$ of cases, and culture requires a delay. ${ }^{2}$ Bacteriological findings remain negative in approximately $20 \%$ of SA cases in the literature, thus the diagnosis is presumptive. ${ }^{3}$ Numerous pathologies, notably crystal-induced and rheumatic diseases, may present in a fashion identical to SA. ${ }^{3}$ In a patient with suspected SA, it is often difficult to evaluate the probability of SA in order to decide on hospitalization or initiation of antibiotic therapy. The sensitivity of clinical signs and laboratory tests is published in a single case series of 74 patients, but large disparities exist due to bias in recruitment and the choice of inclusion criteria. There is no study available on the specificity of clinical signs, and the data on the specificity of laboratory tests are very limited.,

This is a prospective study aimed to establish the predictive value of clinical signs and laboratory tests for the diagnosis of SA in patients referred with a suspicion of SA.

\section{METHOD}

This is a prospective observational cohort study carried out in the emergency and rheumatology departments of the University Hospital, Clermont-Ferrand (primary and secondary referral centre located in a rural region where acquired immune deficiency syndrome [AIDS] and drug abuse are rare). All consecutive patients suspected of having an SA and examined by a rheumatologist over a period of 18 months (between July 2010 and January 2012) were enrolled. There is no validated definition for suspected SA. In order to be as pragmatic as possible and reflect general routine practice, we chose to include all patients for whom the rheumatologist had been contacted for a suspicion of SA independent of the duration, clinical presentation, site, or number of joints involved. Excluded from this study were patients under the age of 18 or those with a joint prosthesis or joint trauma.

For every patient included, informed consent was obtained, and standardized clinical data were recorded. Data included demographics (age, sex), number of joints affected, duration (in weeks), and timing of the onset of symptoms (acute if less than 24 hours or gradual if more than 24 hours), fever $\left(>38^{\circ} \mathrm{C}\left[100^{\circ} \mathrm{F}\right]\right)$, chills, local inflammatory symptoms, visual analogue scale (VAS) for pain at rest and upon movement, localized adenopathy, the existence of an entry site for infection, history of rheumatic disease (rheumatoid arthritis, ankylosing spondyloarthritis, polymyalgia rheumatic, or other) or crystal-induced arthritis (gout, chondrocalcinosis), risk factors for SA (diabetes mellitus, cancer, immunosuppression, alcoholism, renal insufficiency, chronic corticosteroid therapy, or other), treatments received prior to evaluation (nonsteroidal anti-inflammatory agents, colchicine, or antibiotics), as well as the presence of an extra-articular site of infection (endocarditis, spondylodiscitis).

The results of the usual laboratory tests were also recorded (white blood cells $[\mathrm{WBC}] / \mathrm{mm}^{3}$, polymorphonuclear cells $[\mathrm{PMN}] / \mathrm{mm}^{3}$, erythrocyte sedimentation rate $[\mathrm{ESR}]$ in millimeters at the first hour, C-reactive protein $[\mathrm{CRP}]$ in milligrams per litre $[\mathrm{mg} / \mathrm{L}]$, uric acid in micromoles per litre $[\mu \mathrm{mol} / \mathrm{L}])$. The radiological findings suggestive of SA (i.e., reduced joint space width, subchondral demineralization, erosion, or joint destruction) as well as the presence of chondrocalcinosis or a preexisting arthropathy were recorded. Joint ultrasound results were noted if performed. If a joint aspiration were performed, the gross appearance of synovial fluid would be classified by the rheumatologist as clear, turbid, purulent, or bemorrbagic. The synovial fluid was analysed by the bacteriology laboratory for cytology, presence of microcrystals, Gram stain, and culture, while a portion of the fluid was systematically injected into a blood culture tube at the patient's bedside. After the previous examinations and before receiving the analysis of the synovial fluid, the rheumatologist evaluated the probability of SA using a VAS and indicating and documenting the most probable diagnosis. The final diagnosis was made a posteriori using the results of all of the investigations and the course of the disease. In the end, patients were classified into two groups: 1) an SA group, if it was certain (i.e., identification of a microorganism in the joint fluid or via blood culture) or possible (i.e., prescription of antibiotic therapy for at least 3 weeks); or 2) a non-SA group, in cases of crystal-induced arthritis, rheumatic disease, or other defined diagnosis.

This study was conducted under the authorization of the local ethics committee (CPP Sud-Est I, 28/5/2010) and in line with regulatory authorities (12/09/2009). 


\section{Statistical analysis}

The population was described by the number/percentage for categorical variables and by the mean $(+/-$ standard deviation) or median (interquartile interval) for the continuous variables. The normality of the quantitative variables was verified by the Shapiro-Wilk test, and a log transformation was performed when the test was significant. Quantitative data were compared between SA and non-SA groups using the Student's $t$-test or the Mann-Whitney test when the Student's $t$-test conditions were not verified. Categorical data were compared by the chi-squared test or the Fisher's exact test when appropriate. For the $2 \times 2$ contingency tables, the data relating to sensitivity, specificity, negative likelihood ratios (LR-) and positive likelihood ratios (LR+) of all signs and symptoms used to differentiate SA from other causes of similar joint damage were calculated and presented with the $95 \%$ confidence interval (CI) as well as odds ratios (OR). Logistic regression models (with dependent variable SA or non-SA) established the predictive value of clinical signs and laboratory tests for the diagnosis of SA, employing a backward and forward stepwise regression on the factors considered significant in the univariate analysis (entry in the model for $p<0.2^{5,6}$ ) and considering clinical relevance parameters, ${ }^{7,8}$ such as antecedents of rheumatic disease and risk factors (adjustment factors). Results were expressed as OR and 95\% CI. Following these multivariate analyses, a receiver operating characteristic curve was plotted for each proposed model, and their areas under the curve (AUC) were compared. ${ }^{9}$ Tests were two-sided, with a type I error set at $\alpha=0.05$. All analyses were performed using STATA (version 11, StataCorp, College Station, Texas).

\section{RESULTS}

In total, 105 patients with suspected SA were included and of these 29 (27.6\%) were confirmed SA and 9 (8.6\%) were SA-possible. The most frequently affected joints after the knee $(n=63,60 \%)$ were hip $(n=15,14.3 \%)$, wrist $(n=11,9.5 \%)$, ankle $(n=9,8.5 \%)$, shoulder $(n=7,6.6 \%)$, metacarpophalangeal joint $(n=5,4.8 \%)$, elbow $(n=5,4.8 \%)$, and metatarsophalangeal joint ( $n=4,3.8 \%)$, with 15 patients $(14.3 \%)$ presenting with involvement of more than one joint.

For the 29 patients for whom SA was confirmed, the most frequently identified microorganisms were methicillin-sensitive Staphylococcus aureus $(n=17,58.6 \%)$,
Streptococcus $(n=3,10.3 \%)$, and methicillin-resistant $S$. aureus $(n=2,6.7 \%)$. Other germs were identified (Enterobacter aerogenes, Klebsiella pneumoniae, Escherichia coli, Campylobacter spp, Salmonella typhimurium, Neisseria gonorrboeae, and coagulase-negative Staphylococcus).

For all of the nine SA-possible patients, the course of the disease was compatible with the diagnosis of SA with improvement after antibiotics and no other diagnosis considered a posteriori in the following 6 months.

For the 67 patients without SA (non-SA group), the final diagnosis was, in most cases, crystal-induced arthritis $(n=35,33.3 \%)$ (15 patients with gout and 20 with chondrocalcinosis), followed by rheumatic disease $(n=11,10.5 \%)$ ( 8 patients with rheumatoid arthritis, 2 with spondylarthropathy, and 1 with polymyalgia rheumatica). In addition, six patients (5.7\%) had undifferentiated arthritis, six $(5.7 \%)$ had osteoarthritis, four (3.8\%) had hemarthrosis, and five (4.8\%) had another diagnosis (one hematoma of the psoas, enthesopathy of the right rectus femoris, one hydroxyapatite deposition disease, allergic arthritis following viscosupplementation, and popliteal cyst rupture). The clinical characteristics are shown in Table 1.

Patients with SA were younger than those from the non-SA group (58.6 v. 60.5 years, $p=0.03$ ), duration of symptoms was shorter in the non-SA group $(1.8 \mathrm{v}$. 2.6 weeks, $p=0.04)$, and acute onset $(<24$ hours) was more frequent $(72.3 \%$ v. $46 \%, p=0.008)$. When the involved joint was the knee, it was most often non-SA $(68.7 \%$ v. $42.1 \%, p=0.008)$. Involvement of more than one joint was similar in both groups $(p=0.41)$.

The SA group had chills more frequently $(39.5 \% \mathrm{v}$. $17.9 \%, p=0.01)$ but no fever, and local redness $(52.6 \% \mathrm{v}$. $28.4 \%, p=0.01)$. There was no significant difference for local swelling, increased cutaneous heat, tenderness, presence of adenopathy or an extra-articular localization, history of rheumatic disease, risk factors for SA, as well as previous treatments. The presence of an entry site for infection was more common in the SA group $(71.1 \% \mathrm{v}$. $46.3 \%, p=0.01)$. In the non-SA group, history of crystalinduced disease was more frequent $(28.4 \%$ v. $5.3 \%$, $p=0.004)$.

\section{Serum laboratory values}

No difference was found for the WBC count, PMNs, and uric acid $(329 \pm 27 \mathrm{mg} / \mathrm{L}$ in the SA group v. $346 \pm 20 \mathrm{mg} / \mathrm{L}$ in the non-SA group). The ESR and CRP levels were higher in the SA group (respectively as mean $( \pm \mathrm{SD})$, 


\begin{tabular}{|c|c|c|c|c|}
\hline & Total $(n=105)$ & Septic arthritis $(n=38)$ & Non-septic arthritis $(n=67)$ & $P$ \\
\hline \multicolumn{5}{|l|}{ Gender } \\
\hline Male & $62(59.1)$ & $19(50)$ & $43(64.2)$ & 0.16 \\
\hline Age (years) & $59.8 \pm 19.4$ & $58.6 \pm 21.9$ & $60.5 \pm 18$ & $0.03^{*}$ \\
\hline Symptoms duration (weeks) & $2.1 \pm 3.8$ & $2.6 \pm 4.6$ & $1.8 \pm 3.2$ & $0.04^{*}$ \\
\hline Acute onset, $<24 h$ & $64(62.7)$ & $17(46)$ & $47(72.3)$ & $0.008^{*}$ \\
\hline Involvement of more than one joint Site & $15(14.3)$ & $4(10.5)$ & $11(16.4)$ & 0.41 \\
\hline Knee & $63(60)$ & $16(42.1)$ & $46(68.7)$ & $0.008^{*}$ \\
\hline \multicolumn{5}{|l|}{ Clinical signs, } \\
\hline Fever $\left(t^{\circ} \geq 38^{\circ} \mathrm{C}\right)$ & $40(49.4)$ & $17(53.1)$ & $23(46.9)$ & 0.6 \\
\hline Chills & $27(25.7)$ & $15(39.5)$ & $12(17.9)$ & $0.015^{*}$ \\
\hline Swelling & $91(86.7)$ & $34(89.5)$ & $57(85.1)$ & 0.52 \\
\hline Redness & $39(37.1)$ & $20(52.6)$ & $19(28.4)$ & $0.01 *$ \\
\hline Heat & $75(71.4)$ & $29(76.3)$ & $46(68.7)$ & 0.4 \\
\hline Pain at rest (/100) & $54.1 \pm 3$ & $53 \pm 5$ & $54.9 \pm 4$ & 0.07 \\
\hline Pain upon movement (/100) & $75.9 \pm 3$ & $74.7 \pm 4$ & $76.7 \pm 3$ & 0.1 \\
\hline Adenopathy & $7(6.7)$ & $2(5.3)$ & $5(7.5)$ & 0.7 \\
\hline Presence of an entry site for infection & $58(55.2)$ & $27(71.1)$ & $31(46.3)$ & $0.01 *$ \\
\hline Cutaneous & $31(29.5)$ & $13(34.2)$ & $18(26.9)$ & 0.43 \\
\hline Infiltration & $11(10.5)$ & $6(15.8)$ & $5(7.5)$ & 0.18 \\
\hline History of rheumatic disease & $14(13.3)$ & 7 (18.4) & $7(10.4)$ & 0.25 \\
\hline History of crystal-induced arthritis & $21(20)$ & $2(5.3)$ & $19(28.4)$ & $0.004^{*}$ \\
\hline Risk factors for SA & $43(41)$ & $17(44.7)$ & $26(38.8)$ & 0.55 \\
\hline Diabetes mellitus & $12(11.4)$ & $6(15.8)$ & $6(9)$ & 0.3 \\
\hline \multicolumn{5}{|l|}{ Previous treatments } \\
\hline Antibiotics & $21(20)$ & $8(21)$ & $13(19.4)$ & 0.84 \\
\hline NSAID & $29(27.6)$ & $11(29)$ & $18(26.9)$ & 0.82 \\
\hline Colchicine & $9(8.6)$ & $3(7.9)$ & $6(9)$ & 0.85 \\
\hline Extraarticular site of infection (endocarditis, spondylodiscitis) & $3(2.8)$ & $1(1.5)$ & $2(5.3)$ & 0.26 \\
\hline
\end{tabular}

$76.1 \pm 39.8$ v. $45.7 \pm 33.8 \mathrm{~mm} / \mathrm{h}[p=0.002]$ and $135.1 \pm$ 16.7 v. $95.1 \pm 13 \mathrm{mg} / \mathrm{L}[p=0.015])$. An $\mathrm{ESR}>50 \mathrm{~mm} / \mathrm{h}$ $(p=0.005)$ and CRP $>100 \mathrm{mg} / \mathrm{L}(p=0.019)$ were more commonly observed in SA.

\section{Radiography and joint ultrasound}

Radiological findings suggestive of SA were found more often in patients with SA $(29.7$ v. $5.1 \%, p=0.001)$, and there was no difference in the radiological findings of chondrocalcinosis. A joint ultrasound was performed on 48 patients $(45.7 \%)$, and there was no difference in the presence of an effusion between the two groups.

\section{Synovial laboratory test values}

Joint aspiration was performed in $90 \%$ of the cases $(n=94)$. The appearance of the fluid was more commonly purulent $(74 \%$ v. $26 \%, p<0.001)$ in cases of SA, and clear $(100 \%$ v. $0 \%, p=0.007)$ in cases of nonSA. The SA group had a higher mean $(95 \%$ CI $)$ synovial WBC count $\left(54,900[20,000-112,000] / \mathrm{mm}^{3} \mathrm{v}\right.$. $15,000[5,000-36,200], p<0.001)$ as well as a higher level of PMNs ( $85 \%$ v. $72 \%, p=0.001)$. There was no difference regarding the presence of microcrystals. The direct Gram stain was positive in $40 \%(n=14)$ of SA cases.

\section{Opinion of the clinician}

Estimation of the probability of SA before receiving the results of the joint fluid analysis was higher in the SA group $(69.4 \%$ v. $31.4 \%, p<0.001)$. The clinician's opinion was incorrect for 10 patients: 5 with a final SA diagnosis and the other 5 with a final non-SA diagnosis. 
Predictive value of the usual signs for the diagnosis of septic arthritis

\begin{tabular}{|c|c|c|c|c|c|c|c|}
\hline Characteristics & $\underline{\mathrm{n}}$ & Sensitivity \% & Specificity \% & $\mathrm{LR}+$ & LR- & OR & $95 \% \mathrm{Cl}$ \\
\hline \multicolumn{8}{|l|}{ Clinical } \\
\hline Age $>80$ years & 105 & 21 & 84 & 1.28 & 0.94 & 1.36 & $0.5-3.7$ \\
\hline Knee affected & 105 & 42 & 31 & 0.61 & 1.85 & 0.33 & $0.15-0.75$ \\
\hline More than one joint involvement & 105 & 11 & 84 & 0.64 & 1.07 & 0.6 & $0.2-1.9$ \\
\hline Slow onset $(>24 \mathrm{H})$ & 102 & 54 & 72 & 1.95 & 0.64 & 3.07 & $1.3-7.1$ \\
\hline Fever $\left(\geq 38^{\circ} \mathrm{C}\right)$ & 105 & 32 & 69 & 1.13 & 0.88 & 1.01 & $0.4-2.4$ \\
\hline Chills & 105 & 39 & 82 & 2.2 & 0.74 & 2.99 & $1.2-7.3$ \\
\hline Swelling & 105 & 89 & 15 & 1.05 & 0.71 & 1.49 & $0.5-4.8$ \\
\hline Redness & 105 & 53 & 72 & 1.86 & 0.66 & 2.81 & $1.2-6.4$ \\
\hline Heat & 105 & 76 & 31 & 1.11 & 0.76 & 1.47 & $0.6-3.6$ \\
\hline Presence of entry site for infection & 105 & 71 & 54 & 1.54 & 0.54 & 2.85 & $1.2-6.6$ \\
\hline History of rheumatic disease & 105 & 18 & 89 & 1.76 & 0.91 & 1,94 & $0.6-5.8$ \\
\hline History of crystal-induced arthritis & 105 & 5 & 72 & 0.19 & 1.32 & 0.14 & $0-0.6$ \\
\hline Risk factors for SA & 105 & 45 & 61 & 1.15 & 0.9 & 1.28 & $0.6-2.8$ \\
\hline \multicolumn{8}{|l|}{ Laboratory tests } \\
\hline Serum WBC count $>10000 / \mathrm{mm}^{3}$ & 105 & 50 & 61 & 1.29 & 0.82 & 1.58 & $0.7-3.5$ \\
\hline $\mathrm{ESR}>15 \mathrm{~mm}$ & 75 & 94 & 23 & 1.22 & 0.27 & 4.55 & 1-infinite \\
\hline $\mathrm{ESR}>50 \mathrm{~mm}$ & 75 & 72 & 60 & 1.82 & 0.47 & 3.91 & $1.5-10.3$ \\
\hline $\mathrm{ESR}>100 \mathrm{~mm}$ & 75 & 34 & 84 & 2.11 & 0.78 & 2.69 & $0.9-7.8$ \\
\hline $\mathrm{CRP}>15 \mathrm{mg} / \mathrm{L}$ & 105 & 92 & 18 & 1.12 & 0.44 & 2.55 & $0.7-9$ \\
\hline $\mathrm{CRP}>100 \mathrm{mg} / \mathrm{L}$ & 105 & 58 & 66 & 1.69 & 0.64 & 2.63 & $1.2-5.9$ \\
\hline Uric acid $>420 \mathrm{mg} / \mathrm{L}$ & 70 & 14 & 75 & 0.58 & 1.14 & 0.51 & $0.1-1.9$ \\
\hline \multicolumn{8}{|l|}{ Radiological } \\
\hline Radiological findings suggestive of SA & 96 & 30 & 95 & 5.8 & 0.74 & 7.9 & $2.1-28.5$ \\
\hline Radiological findings suggestive of chondrocalcinosis & 96 & 16 & 68 & 0.5 & 1.24 & 0.41 & $0.2-1.1$ \\
\hline \multicolumn{8}{|l|}{ Synovial fluid examination } \\
\hline Gross appearance & 94 & & & & & & \\
\hline Clear & & $\mathbf{0}$ & 81 & 0 & 1.23 & 0 & $0-0.5$ \\
\hline Turbid & & 26 & 44 & 0.46 & 1.69 & 0.27 & $0.1-0.7$ \\
\hline Purulent & & 57 & 88 & 4.73 & 0.49 & 9.71 & $3.5-26.9$ \\
\hline Hemorrhagic & & 17 & 86 & 1.3 & 0.96 & 1.3 & $0.4-4$ \\
\hline WBC count & 83 & & & & & & \\
\hline$>10000 / \mu \mathrm{L}$ & & 89 & 35 & 1.36 & 0.31 & 4.4 & $1.2-15.3$ \\
\hline$>50000 / \mu \mathrm{L}$ & & 57 & 82 & 3.14 & 0.52 & 6 & $2.2-16.4$ \\
\hline$>100000 / \mu \mathrm{L}$ & & 29 & 93 & 3.93 & 0.77 & 5.1 & $1.5-17.8$ \\
\hline PMNs $>90 \%$ & 85 & 42 & 82 & 2.26 & 0.71 & 3.2 & $1.2-8.4$ \\
\hline Presence of microcrystals & 90 & 24 & 58 & 0.58 & 1.31 & 0.44 & $0.2-1.1$ \\
\hline Positive Direct Gram Stain & 94 & 40 & 100 & infinite & 0.6 & infinite & 9.8-infinite \\
\hline
\end{tabular}

The probability of SA estimated by the clinician was correlated to symptom duration $(p=0.008)$, fever $(p=0.002)$, chills $(p=0.006)$, local redness $(p=0.004)$, existence of an entry site for infection $(p=0.003)$, history of crystal-induced arthritis $(p=0.03)$, serum WBC count $(p=0.025)$, ESR $(p=0.003)$, CRP level $(p=0.004)$, radiological findings of $\mathrm{SA}(p=0.02)$, gross appearance of the synovial fluid $(p<0.001)$, and synovial WBC count $(p=0.02)$.
The sensitivity, specificity, likelihood ratios, and odds ratios of the clinical signs, laboratory tests, radiological, and ultrasound findings are shown in Table 2.

\section{Multivariate analysis}

In the multivariate analysis, chills $(\mathrm{OR}=4.7,95 \% \mathrm{CI}$ 1.3-17.1), history of crystal-induced arthritis (OR = $0.09,95 \%$ CI $0.01-0.9)$, purulent appearance of the 


\begin{tabular}{|c|c|c|}
\hline & Model 1 (๑) & Model $2(\boldsymbol{\Lambda})$ \\
\hline & OR $(95 \% \mathrm{Cl})$ & OR $(95 \% \mathrm{Cl})$ \\
\hline Chills & $3.1(0.9-10.4)$ & $4.9(1.3-18.2)$ \\
\hline History of crystal-induced arthritis & $0.05(0.01-0.5)$ & $0.08(0.01-0.8)$ \\
\hline Radiological findings suggestive of SA & $7.1(1.2-37.9)$ & \\
\hline Purulent appearance of synovial fluid & $8.4(2.5-28.5)$ & \\
\hline Synovial WBC count $>50000 / \mathrm{mm}^{3}$ & & $16.6(2.8-97.5)$ \\
\hline Risk factor for SA & & $3.1(0.87-11)$ \\
\hline Presence of an entry site for infection & & $3(0.9-10.2)$ \\
\hline$A \cup C$ & 0.85 & 0.87 \\
\hline Sensitivity & 0.65 & 0.64 \\
\hline Specificity & 0.86 & 0.85 \\
\hline$P P V$ & 0.76 & 0.69 \\
\hline NPV & 0.79 & 0.82 \\
\hline
\end{tabular}

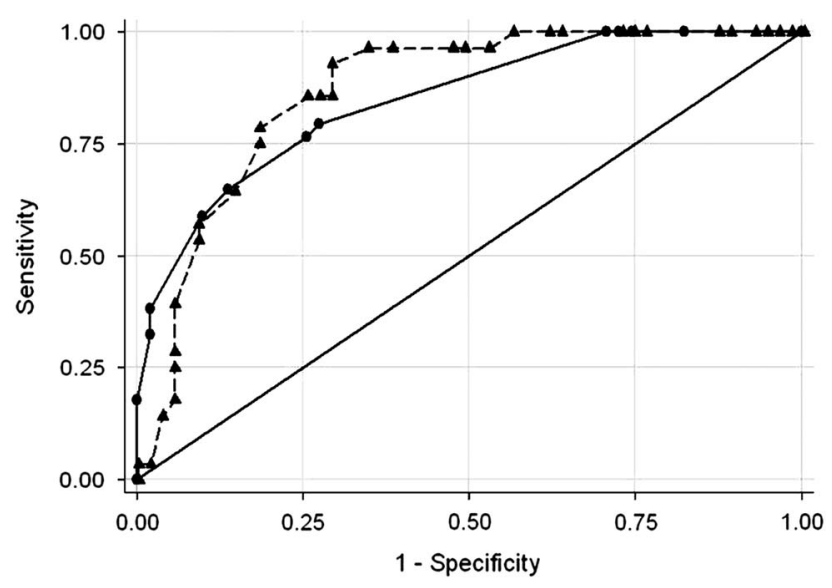

Figure 1. Logistic regression models and ROC curves for the diagnosis of septic arthritis. OR: odds ratios; $\mathrm{Cl}$ : confidence interval; AUC: area under the curve; NPV: negative predictive value; PPV: positive predictive value.

synovial fluid $(\mathrm{OR}=8.4,95 \%$ CI 2.4-28.5), synovial $\mathrm{WBC}$ count $>50,000 / \mathrm{mm}^{3}(\mathrm{OR}=6.8,95 \%$ CI $1.3-36)$, and suggestive radiological signs $(\mathrm{OR}=7.1,95 \% \mathrm{CI}$ 13-37.9) were significantly associated with SA.

Two logistic regression models, one with and one without radiological findings, were selected (Figure 1). Model 1 includes the parameters: chills, history of crystal-induced arthritis, radiological findings of SA, and purulent appearance of the synovial fluid; the AUC was 0.84 . This model may correspond to the usual practice in an emergency, when the clinician has the clinical and radiological parameters and the appearance of the synovial fluid but not the results of its analysis. Model 2 includes the parameters: chills, history of crystal-induced arthritis, synovial $\mathrm{WBC}>50,000 / \mathrm{mm}^{3}$, existence of an entry site for infection, and risk factors for SA; the AUC was 0.87 .

The univariable and multivariable analysis was repeated, excluding all of the "possible" SA patients $(n=9)$ without any changes in the outcomes.

\section{DISCUSSION}

In our cohort of patients with suspected SA, 36\% were confirmed or probable SA. The presence of chills, a history of crystal-induced arthritis, radiological findings suggestive of SA, as well as the gross appearance of the synovial fluid and its cellularity were the parameters that best differentiated SA from non-SA cases.

While waiting for the bacteriological results, the diagnosis of SA is based on a review of risk factors, as well as clinical signs and laboratory tests. Age $>80$ years, diabetes, and rheumatoid arthritis, which are risk factors for SA, have a comparable frequency in SA and non-SA groups. ${ }^{10}$ On the contrary, a history of crystalinduced arthritis (gout or chondrocalcinosis) was more frequent in the non-SA group ( $28 \%$ v. $5 \%)$, and its presence decreased the probability of SA $(\mathrm{LR}+0.58)$. In our study, chills appeared to be more frequent, present in $40 \%$ of SA cases, and an independent factor in multivariate analysis; however, the LR + was only 2.2 and its sensitivity was weak, notably $19 \%$ based on a prior study. ${ }^{2}$ The serum WBC count did not differ between the SA and non-SA groups. An ESR $>50 \mathrm{~mm}$ at 1 hour and a CRP $>100 \mathrm{mg} / \mathrm{L}$ were weakly associated with SA. The specificity was mediocre in the few studies that evaluated this parameter, ${ }^{11,12}$ and a recent review of the literature concluded that, regardless of the threshold used, ESR and CRP levels did not significantly increase the posttest probability of SA. ${ }^{2}$

Thirty percent of patients already had radiological findings suggestive of SA at diagnosis. Although they were associated with a major diagnostic delay, radiological findings suggestive of SA remain useful $(L R+5.8)$. In prior cases series, these signs were present in approximately half of the SA cases ${ }^{1}$; however, the specificity was not reported. The definition of the radiological findings (i.e., reduced joint space width, bone demineralization, erosion, and destruction) poses a problem. The frequency of radiological findings of chondrocalcinosis was not significantly different between the two groups.

The gross appearance of synovial fluid as evaluated by the clinician was a valid parameter in excluding SA 
when the fluid was clear (sensitivity null) or to consider it when it was purulent $(\mathrm{LR}+4.7)$. In any case, its interpretation is often subjective and difficult to standardize. The cellularity of synovial fluid was considered to be the best non-bacteriological test for the diagnosis of SA. In a review of the literature, the probability of the diagnosis of SA increased with an increase in the synovial WBC count. ${ }^{2}$ In a meta-analysis, the sensitivity was $56 \%$ and $19 \%$, and the specificity was $90 \%$ and $99 \%$ for a cellularity of 50,000 and $100,000 / \mathrm{mm}^{3}$, respectively. ${ }^{4}$ These studies are heterogeneous and did not include, in a prospective manner, patients with a suspected SA. In our study, the usefulness of this parameter was minimal. The sensitivity of direct Gram stain of synovial fluid was $40 \%$ in our study, and, in a review of the literature, it varied between $29 \%$ and $65 \% .^{4}$ Its specificity, which has not previously been studied, was $100 \%$ in our study. Curiously, the presence of microcrystals in the synovial fluid did not decrease the probability of SA, because $24 \%$ of the patients with SA had microcrystals. A similar frequency (22 of 104, $21 \%$ ) was shown in a recent study, and the presence of microcrystals did not exclude SA. ${ }^{13}$ Finally, the opinion of the clinician who has the basic biological results possibly even the macroscopic appearance of the synovial fluid but not the result of its analysis, is relevant but not consistent; SA was not the most probable diagnosis in $5 / 38(13 \%)$ of the SA cases. This could be explained by an over-reliance on the diagnostic value of fever and elevated inflammatory markers.

Our study has important limitations. The first challenge in the methodology is to decide what to do with cases of SA when bacteriological samples are negative. The prevalence of this situation ranges from $7 \%$ to $35 \%$ with significant differences in large case series. ${ }^{14-16}$ To exclude these cases would lead to an underestimation of the frequency of SA. Second, none of the diagnostic criteria have been validated in adults; therefore, a pragmatic definition was adopted to include both bacteriological positive and negative SA as defined as: SA was considered probable when the clinician retained the diagnosis and treated accordingly, with antibiotic therapy for at least 3 weeks. With this definition, 24\% of the patients had SA without bacteriological documentation. The analysis performed following the exclusion of these patients did not modify the study results. Given the large diversity at presentation, it is also challenging to define suspected SA. Painful swelling of the joint does not apply to deep joints. Acute monoarthritis does not apply to either $10 \%$ of SA cases, which involve more than one joint, ${ }^{17}$ or to a subacute or chronic presentation. Limiting the cases to those where a rheumatologist was contacted for a suspicion of SA was a pragmatic way to define suspected SA. When using these criteria, the prevalence of SA, which is the pretest probability, was $36 \%$ for those with suspected SA and $28 \%$ for bacteriologically documented SA. These were similar prevalence estimates to the pretest probability of bacteriologically proven SA at $21 \%$ and $27 \%$ in two prior studies. ${ }^{18,19}$

\section{CONCLUSION}

No clinical sign or non-bacteriological test, when taken alone, appears to be of value for the differentiation of SA from non-SA pathology, but the association of several factors, notably chills, the lack of any history of crystal-induced arthritis, radiological findings compatible with SA, and the appearance and cellularity of synovial fluid may combine to be suggestive as demonstrated in the two logistic regression models (AUC 0.85 and 0.87). In anticipation of having reliable markers of infection, this could serve to derive a score in patients with a suspected SA in order to estimate the diagnostic probability of SA and guide decisions on hospitalization or prescription of antibiotics. Both of these models require prospective validation prior to implementation.

Acknowledgements: The author wishes to thank Drs. Marielle Vayssade, Sandrine Mallochet-Guinamand, Anne Tournadre, Baptiste Glace, and Zuzana Tatar for their collection of data.

Competing interests: None declared.

\section{REFERENCES}

1. Dubost JJ, Soubrier M, Sauvezie B. Pyogenic arthritis in adults. Foint Bone Spine 2000;67(1):11-21.

2. Margaretten ME, Kohlwes J, Moore D, Bent S. Does this adult patient have septic arthritis? $7 A M A$ 2007;297(13): 1478-88.

3. Eberst-Ledoux J, Tournadre A, Mathieu S, et al. Septic arthritis with negative bacteriological findings in adult native joints: a retrospective study of 74 cases. Foint Bone Spine 2012;79(2):156-9.

4. Carpenter C, Schuur D, Everett W, Pines J. Evidencebased diagnostics: adult septic arthritis. Acad Emerg Med 2011;18:781-96. 
5. Lee K, Koval JJ. Determination of the best significance level in forward logistic regression. Communications in Statistics-Simulations 1997;26(2):559-75.

6. Shtatland ES, Cain E, Barton MB. The perils of stepwise logistic regression and how to escape them using information criteria and the Output Delivery System. SUGI'26 Proceedings, Paper 222-26. Cary, NC: SAS Institute Inc; 2001.

7. Hosmer DW, Lemeshow S. Applied logistic regression. New York: John Wiley \& Sons, Inc; 1989.

8. Steyerberg EW, Eijkemans MJC, Harrell FE Jr, Habbema JDF. Prognostic modeling with logistic regression analysis: a comparison of selection and estimation methods in small data sets. Stat Med 2000;19(8):1059-79.

9. DeLong ER, DeLong DM, Clarke-Pearson DL. Comparing the areas under two or more correlated receiver operating characteristic curves: a nonparametric approach. Biometrics 1988;44:837-45.

10. Kaandorp CJ, Van Schaardenburg D, Krijnen P, et al. Risk factors for septic arthritis in patients with joint disease. A prospective study. Arthritis Rheum 1995;38(12): 1819-25.

11. Kaandorp CJ, Dinant HJ, van de Laar MA, et al. Incidence and sources of native and prosthetic joint infection: a community based prospective survey. Ann Rheum Dis 1997;56(8):470-5.
12. Hariharan P, Kabrhel C. Sensitivity of erythrocyte sedimentation rate and C-reactive protein for the exclusion of septic arthritis in emergency department patients. 7 Emerg Med 2011;40(4):428-31.

13. Gupta MN, Sturrock RD, Field M. Prospective comparative study of patients with culture proven and high suspicion of adult onset septic arthritis. Ann Rheum Dis 2003;62(4):327-31.

14. Dubost JJ, Fis I, Denis P, et al. Polyarticular septic arthritis. Medicine (Baltimore) 1993;72:296-310.

15. Jeng GW, Wang CR, Liu ST, et al. Measurement of synovial tumor necrosis factor-alpha in diagnosing emergency patients with bacterial arthritis. Am 7 Emerg Med 1997;15(7):626-9.

16. Talebi-Taher $M$, Shirani F, Nikanjam N, Shekarabi $M$. Septic versus inflammatory arthritis: discriminating the ability of serum inflammatory markers. Rheumatol Int 2013;33(2): 319-324.

17. Li SF, Cassidy C, Chang C, et al. Diagnostic utility of laboratory tests in septic arthritis. Emerg Med $\mathcal{F}$ 2007;24(2):75-7.

18. Ernst AA, Weiss SJ, Tracy LA, Weiss NR. Usefulness of CRP and ESR in predicting septic joints. South Med 7 2010;103(6):522-6.

19. Papanicolas LE, Hakendorf P, Gordon DL. Concomitant septic arthritis in crystal monoarthritis. $\mathcal{F}$ Rheumatol 2012; 39(1):157-60. 